\title{
El culto a los muertos milagrosos en Venezuela: ¿Santos, espíritus o héroes?
}

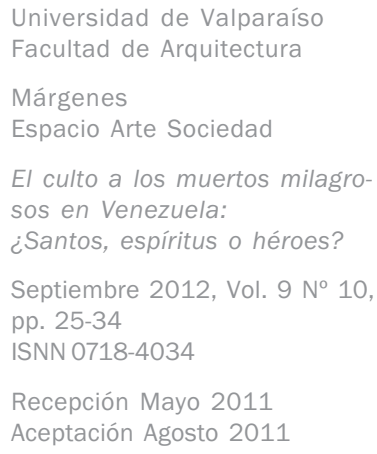

$>$ Licenciado en Historia, graduado en la Escuela de Historia de la Universidad de Los Andes (Mérida). Magíster en Etnología y profesor Agregado de Departamento de Antropología y Sociología de la misma Universidad. Ha publicado artículos de historia y antropología en revistas Nacionales e Internacionales. Publicó en 2009 el libro Muertos, fantasmas y héroes. El culto a los muertos milagrosos en Venezuela, editado por el Consejo de Publicaciones de la ULA.

\section{Resumen}

En este artículo presentamos los rasgos característicos del culto a los muertos milagrosos en Venezuela, para ello presentaremos brevemente las "biografías míticas", resumen de los relatos de los devotos y creyentes que cuentan acerca de estos muertos de la ciudad de Mérida, de los Andes venezolano. Hemos escogido una muestra de estos muertos para caracterizar el mito y el culto a éstos, considerándolos como parte de un imaginario y una cosmovisión sobre la muerte, lo cual plantea el problema de cómo deben considerarse: ¿santos, espíritus o héroes?

\section{Palabras clave}

muertos milagrosos, santos populares, héroes, Mérida, Venezuela.

\section{The Cult to the Miraculous Dead in Venezuela: Saints, spirits or heroes?}

\section{Abstract}

Characteristic features of the cult of the miraculous dead in Venezuela are described in this paper. "Mythical biographies", a summary of the stories of devotees and believers who tell about these dead of Merida city, in the Venezuelan Andes. A sample of these dead was selected to characterize the myth and the cult to these dead, considering them as part of an imaginary and a worldview on death. The latter rises the question of how they should be considered: as saints, spirits or heroes?

\section{Key words}

miraculous dead, popular saints, heroes, Merida, Venezuela.

Le culte aux morts miraculeux au Venezuela, des Saints, des esprits ou des héros?

\section{Résumé}

Dans cet article, on présente les traits caractéristiques du culte aux morts au Venezuela, pour cela nous présenterons brièvement les biographies mythiques, le résumé des récits des dévots et des croyants, qui racontent à propos de ces morts de la ville de Mérida, des Andes Vénézuélien.

Pour caractériser le mite et le culte à ces morts, on a choisi un échantillon des récits à propos de ces morts, en les considérant comme partie d'un imaginaire et d'une cosmovision sur la mort, la quelle projette le problème de comment on doit les considérer, des Saints, des esprits ou des héros?

\section{Mots clés}

morts miraculeux, saints populaires, héros, Mérida, Venezuela 
La presencia de los muertos en la vida cotidiana de los venezolanos es un dato inobjetable para cualquier observador atento de nuestra sociedad. Es una presencia rutinaria y masiva en la vida de los venezolanos, juegan un papel relevante en la vida de los vivos, tanto en lo privado como en lo público ${ }^{1}$. Varios ejemplos podemos ofrecer: las historias de fantasmas o aparecidos que se cuentan en la familiaridad del hogar o con amigos y conocidos; las creencias y prácticas cotidianas vinculadas con los muertos o relacionados con ellos, como dejarle vasos con agua, escuchar y sentir ruidos que denotan la presencia de algún muerto, el usar objetos que pertenecían a estos como protección, la presencia de los muertos en los sueños lo cual tiene un significado para los vivos; los altares caseros compuestos por santos católicos, muertos familiares y milagrosos a los cuales se les pide protección, favores, y con los cuales se convive cotidianamente en el espacio doméstico; la presencia de algunos héroes patrios como Bolívar, El Libertador, en la vida política y cotidiana, como especie de antepasado colectivo, muerto familiar que ocupa todos los espacios de la nación²; la construcción de tumbas y capillitas a orillas de carretera para el "alma" de las personas que murieron por una muerte violenta o accidental (Franco, 2009, pp. 90-96); la presencia preeminente de los espíritus de muertos en el culto a María Lionza ${ }^{3}$ y y el culto a los muertos milagrosos que constituye un sistema de creencias y prácticas aparte, que se distingue del catolicismo y del espiritismo marialioncero.

En este artículo pretendemos caracterizar uno de estos fenómenos, el llamado culto a los muertos milagrosos ${ }^{4}$, para ello presentaremos brevemente la historia acerca de los muertos milagrosos de la ciudad de Mérida ${ }^{5}$ en Venezuela, lo cual es una escogencia más bien arbitraria en función de presentar una muestra de una figura que se presenta en todo el país ${ }^{6}$. Es un fenómeno que se encuentra entrelazado, en una urdimbre difícil de separar, con las creencias y prácticas arriba señaladas. En cuanto a su origen, es difícil determinar qué pertenece a qué, o como los científicos más sesudos y sistemáticos quisieran establecer, qué elemento es indígena, qué estructura es católica, o qué práctica vamos a considerar afrodescendiente. No afirmo que esto no sea interesante sino más bien que parte de una premisa errada o prejuiciada; al obviar que este fenómeno aunque viene del pasado es también contemporáneo y es el resultado de un proceso de transculturación difícil de seguir. Es mucho más fructífero considerar que existen varios sistemas de prácticas y creencias que en la actualidad se confrontan, pelean, se fusionan o se intentan anular sin éxito, y que los adeptos, es decir los venezolanos -y creo que también los latinoamericanos- se mueven, se repliegan, transitan por todos estos sistemas, durante sus vidas o en el transcurso del día, no sin conflictos (Briceño Guerrero, 1994). Las actitudes, las creencias y las prácticas sobre la muerte las entendemos según esta premisa.

\section{SOBRE EL "CATOLICISMO POPULAR"}

Venezuela se considera en cualquier libro para turistas o en libros como Almanaque Mundial, como principalmente católica, algo que cualquier antropólogo refutaría con facilidad. Aunque se habla de un "catolicismo popular" opuesto al "catolicismo oficial" creemos que debería hablarse más bien de un catolicismo de teólogos y eclesiásticos y otro el que practican
Ios católicos comunes, que nunca ha sido el mismo y en ocasiones es opuesto. Como Delgado (1993) aclaró muy bien con ejemplos para el catolicismo español:

...la religión llamada el catolicismo, tal y como aparece formulada por las instancias teologales, lo es -una religión- en la medida en que es un sistema de conceptualización en que lo santo es el valor central. Los obstáculos surgen cuando el científico (que ha rehusado el uso del término religión en el sentido a la vez teológico y vulgarizado, a la manera como se habla del budismo, islamismo, etc.) intenta identificar algo conocido como la religión católica con una institución encastrada en la cultura y emanada de ella y de sus necesidades. Pero la historia de la Iglesia católica es, en cierto modo, la historia de su lucha por conseguir un acomodo en la sociedad a la que dirigía sus mensajes propagandísticos, lucha en la que casi nunca ha obtenido éxito absoluto. O dicho de otro modo: en los países donde ha tenido influencia, la religión eclesial ha debido luchar desventajosamente contra la indiferencia e incluso la hostilidad de la mayor parte de la población, que la ha marginado de su vida religiosa, accediendo finalmente a otorgarle un papel inestable, de cuya fragilidad hay innumerables ejemplos históricos bien ilustrativos. (s/p).

La presión y el control que pretende ejercer la Iglesia católica con el culto a los Muertos Milagrosos es un ejemplo de este fracaso. La Iglesia aplica un proceso administrativo y legal para canonizar a las figuras que cumplen con el modelo de santo católico; sin embargo, la gente escoge a sus propios modelos, por ello a muchos de los muertos milagrosos se les dice que son "santos" populares, que la gente, el colectivo, la comunidad los ha "santificado" ¿Qué significa realmente esta frase? Los muertos milagrosos en Venezuela son personajes, según los relatos de sus creyentes $-y$ aquí no importa si realmente existieron o no-, cuyas vidas no corresponden con el ideal del santo católico, sus biografías míticas resaltan una vida contraria al orden social: son ladrones, prostitutas, alcohólicos, bandoleros, malandros, guerrilleros, etc., sólo muy pocos parecen cumplir con los requisitos de una vida "santa", ascética, como quiere el modelo católico ${ }^{7}$. Los mismos devotos, sin embargo, están conscientes de estas diferencias que a veces se constituyen en abiertas contradicciones: ¿un santo malandro, una santa prostituta? La Iglesia Católica, realmente, no ha podido controlar la creación de estos muertos milagrosos, no obstante, a los devotos les encantaría -y muchos luchan por ello- que fueran reconocidos oficialmente como santos.

\section{LA NOCIÓN DE MUERTO MILAGROSO}

En Venezuela muerto milagroso -o ánima milagrosa (Pollakeltz: 1987 ) - es una noción popular que designa a aquellas personas que luego de su muerte hacen favores y milagros a los vivos, distinguiéndose así de los muertos comunes y de otros muertos públicos. Son venerados de manera "íntima", familiar o públicamente en la tumba, en el cementerio, en el lugar donde murieron o en un altar casero (de María Lionza o uno "estrictamente" católico), o sin necesidad de ello. El culto de estos muertos, primeramente, tiene una importancia local, incluso meramente familiar, pero gracias a distintos canales de los cuales el más importante es la oralidad pero que hoy 
día incluye incluso la internet- algunos llegan a alcanzar fama nacional.

El cementerio es uno de los lugares públicos más importante donde se le rinde culto a estos muertos, porque es allí donde usualmente está su cadáver y su tumba; sin embargo, a muchos se les venera en el lugar donde acaeció su muerte. En todo caso, los sitios donde reciben culto público pueden multiplicarse y algunos de ellos se convierten en lugar de peregrinación. En el caso de la ciudad de Mérida el cementerio es el lugar público de veneración, aunque uno de los muertos (Machera) tiene una capillita en el lugar de su muerte. Todos estos espacios son visitados por sus devotos para solicitar favores. La "visita" muchas veces tiene un sentido de familiaridad: "darle una vuelta", "presentarle los respetos" y si se necesita algo se aprovecha para pedir algún favor o pagar una "deuda" pendiente. Esta visita usualmente va acompañada de exvotos para el santo. Existe también un culto íntimo o privado, en el cual el devoto pide favores a su muerto preferido en la intimidad de su casa, en el altar hogareño -si lo tuviera-, en cualquier momento o lugar cuando lo requiera; en este sentido, no siempre hay necesidad de visitar al muerto en el cementerio o al lugar de su tumba. Aunque hay que reconocer que el peregrinaje a la tumba o al cementerio es un evento importante en la solicitud y pago de favores a estos muertos milagrosos.

Las ofrendas que se entregan al muerto son generalmente flores, velas, agua, licor, frutas, cigarrillos (a veces con marihuana), placas de agradecimiento, cuadernos de apuntes, etc. Otros exvotos comunes son las figuras alusivas al favor pedido: fotos $u$ objetos de casas en miniatura hecha en cartón u otro material, carros, camioncitos, figuras de novios, etc. Uno de los exvotos más usados son los llamados milagritos, que se consiguen generalmente en las "perfumerías" males, manos, hombres, mujeres, niños o niñas, piernas, brazos, casas, figuras de otros santos, partes del cuerpo, etc.) y representan el favor o el milagro que el devoto espera le sea concedido. Por ejemplo, si una mujer está enferma del pecho (un cáncer de mamas) o de un brazo, se le pide al muerto milagroso que la cure, ella entonces le lleva a su tumba un milagrito con forma de pechos de mujer o uno que se asemeja a un brazo; si un pescador solicita un favor relacionado con su oficio, luego de cumplido su deseo puede llevarle al muerto un milagrito en forma de pez ${ }^{9}$. El exvoto o milagrito es un regalo, un obsequio, una "cortesía", que establece un intercambio, una relación de reciprocidad (una especie de "don") entre el vivo y el muerto. Este es como una divinidad que interviene mágicamente tanto en los detalles más pequeños de la vida, como en los más graves e importantes, siempre a petición del creyente. El culto supone, pues, una relación ritual y sagrada con la figura del muerto milagroso que se concretiza en la solicitud de favores y milagros y la concesión de estos por parte del muerto. Como en todo pacto religioso entre devoto y divinidad se trata de una transacción ...en la que cada una de las partes se ve obligada a cumplir, en una economía cosmogónica que engloba, como en la Antigüedad y en el mundo prehispánico, lo terrenal y lo sobrenatural. (Alberro, 2000, p. 28). Para los creyentes y devotos en los muertos milagrosos (lo cual incluye a la mayoría de los católicos venezolanos) la disyuntiva entre una divinidad única y varias divinidades no constituye ningún problema: no significa una contradicción o no importa. Todos los muertos milagrosos constituyen entidades independientes, tutelares, protectoras, familiares, con las cuales se establece una afectividad casi humana: "cada quien con su muerto". Pero como todo favor, hay que devolverlo. Algunos de ellos, no todos, son vengativos y peligrosos cuando la promesa no es cumplida por el devoto; no obstante, a veces lo que se promete es muy sencillo de cumplir.

\section{ALGUNOS MUERTOS MILAGROSOS DE LA CIUDAD DE MÉRIDA, VENEZUELA}

Desde muy temprano, la ciudad de Mérida ha sido pródiga en muertos milagrosos. Uno de los primeros nació durante la colonia: Gregorio de la Rivera. Es un personaje histórico de esta ciudad, perteneciente a la élite colonial y con vinculaciones familiares en Santa Fe de Bogotá. Vivió en el primer cuarto del siglo XVIII y murió fusilado por haber asesinado a un sacerdote. Su culto permanece hasta hoy en día y se ha difundido por buena parte de Venezuela. Sus devotos actuales no conocen mucho la historia de su vida y muerte, aunque reconocen su poder para "conseguir las cosas perdidas", además en el culto de María Lionza existe una oración donde se invoca su "espíritu" para recuperar el dinero prestado y para cuidar la riqueza (Blanco, 1988, p. 91). A pesar del desconocimiento de su "leyenda", el mito de Gregorio Rivera ha llegado hasta al presente gracias a los relatos de los favores que este muerto concede a sus devotos y también por la existencia de dos textos de dos escritores merideños de la tercera década del siglo $X X^{10}$. Este personaje por celos a su esposa asesinó a un sacerdote durante una semana santa, lo que causó gran revuelo en el pueblo por la maldición que les podía caer ante el sacrílego suceso. Rivera intenta escapar pero de manera misteriosa regresa una y otra vez al centro del pueblo. Se arrepiente, se entrega, es enjuiciado y condenado a muerte. Es fusilado y no ahorcado por ser una persona con linaje. EI fusilamiento es llevado a cabo por soldado inexpertos que le disparan sin efectividad y le causan un terrible sufrimiento. Luego de su muerte comienza a difundirse los relatos acerca de los favores y milagros que concede. En una versión de internet la historia del asesinato se transfigura en una historia de amor tipo Romeo y Julieta ${ }^{11}$.

En la actualidad el cementerio El Espejo de la ciudad de Mérida recibe regularmente devotos que visitan las tumbas de varios muertos milagrosos en busca de favores y milagros o para pagar algún beneficio recibido. Estos son: Machera, Jacinto Plaza, el Soldado y Alberto Carnevali. Expongamos muy brevemente la "biografía mítica" que los devotos cuentan y repiten sobre ellos.

Jacinto Plaza murió en 1900. Era de origen indígena y muy pobre. Llegó a ser arriero ${ }^{12}$ y más tarde dueño de tierras que perdería por culpa de su socio. Luego se hizo pequeño comerciante. Su tienda ubicada en la ciudad de Mérida era el sitio predilecto de muchos campesinos pobres que llegaban de los campos, les ofrecía buen dinero por sus cosechas y posada para que se resguardaran durante los días que visitaban la ciudad. Esta generosidad le granjeó el odio de los comerciantes más ricos de la ciudad, quienes entonces no podían aprovecharse de los pequeños productores. Dejaba comida o dinero en las casas de personas muy pobres que no tenían que comer; 


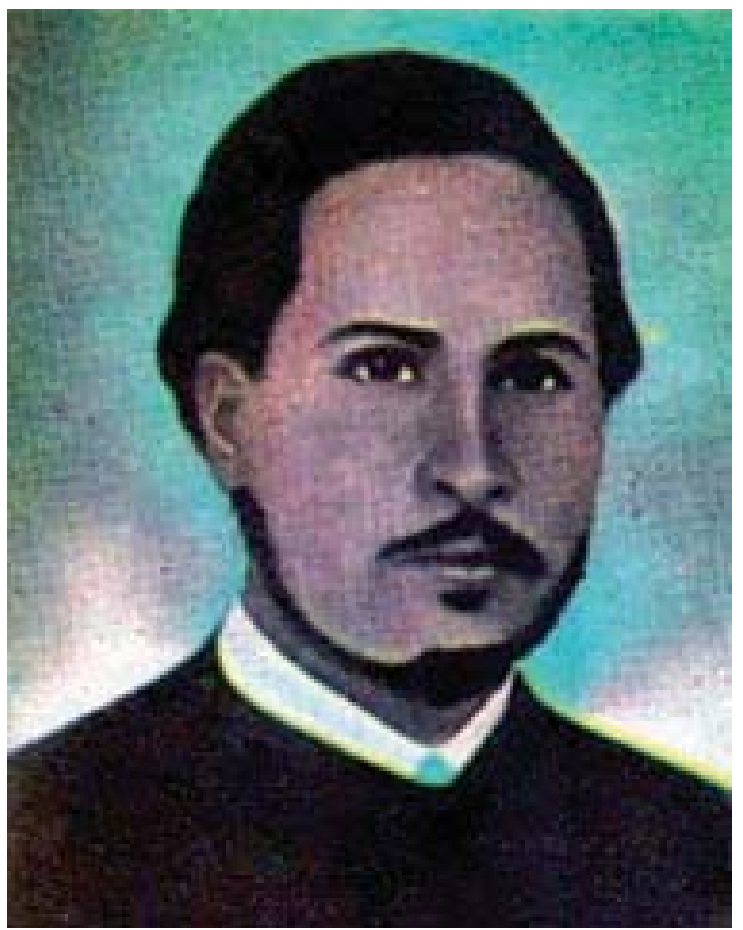

Figura 1 Estampita de Jacinto Plaza tomada de una Estampita. Fotografía F. Franco

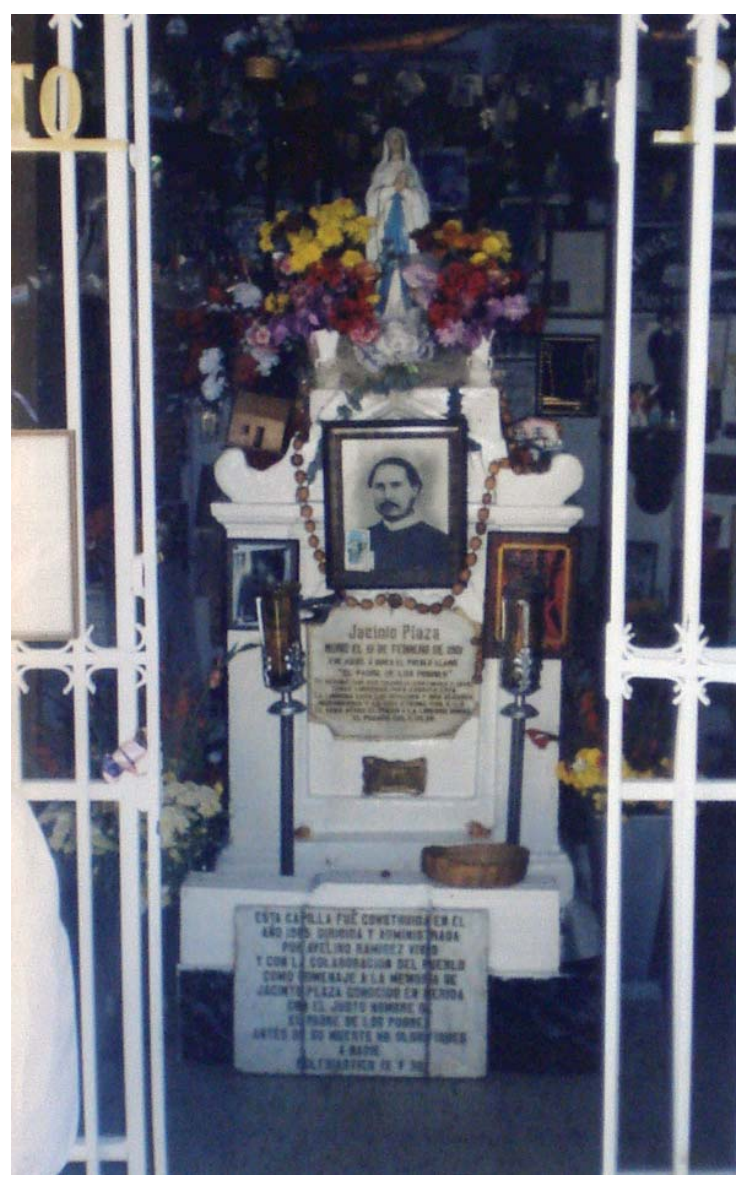

Figura 2 Tumba de Jacinto Plaza. Cementerio El Espejo. Ciudad de Mérida, Venezuela. Fotografía F. Franco asimismo pagaba los gastos fúnebres de aquellos que al morirse no tenían nada, proporcionándoles un ataúd y un entierro decente. Por todo esto era y es llamado el "padre de los pobres". Era, además, ateo y anticlerical lo que le trajo conflictos con los sacerdotes y la iglesia católica. Cuando muere (de "muerte natural") se le niega la sepultura en "campo santo", sin embargo más tarde, según algunos devotos, producto de un prodigio, su cadáver es depositado en el cementerio. Muere en 1901 y durante casi todo el siglo XX ha sido el muerto milagroso más prestigioso de la ciudad de Mérida.

Los relatos sobre Jacinto Plaza, al igual que los de otros muertos milagrosos, han traspasado sus límites dentro del grupo social donde nacieron y se han extendido a una población mayor. En este caso, algunos autores, como intelectuales interesados por el pasado y las tradiciones de la ciudad de Mérida, han intentado "rescatarlo". Si bien este personaje no ha ocupado ningún lugar central en ningún estudio historiográfico, o algo parecido, se ha intentado recuperar de él una imagen de hombre rebelde y caritativo, representante de una clase oprimida por los ricos e injustamente tratada por la Iglesia. Humberto Tejera señala que Jacinto Plaza había sido enterrado en las tierras de un tal Sr. Nicomedes en Santa Juana, por la negativa de la Iglesia de darle cristiana sepultura. Según este autor, este suceso dio que hablar en la ciudad:

...Grave impresión había causado en aquel tiempo la negativa de sepultura en sagrado la más bueno de los hombres, al dadivoso para los pobres, al popular tendero Jacinto Plaza quien hubo de ser enterrado en un potrero de don Nicomedes, con impresionante letrero entre las altas yerbas que comían su tumba, que fue puesto por los liberales y que decía 'El agua apaga el fuego y la limosna el pecado'... (Subrayado autor) (Tejera, 1974, p. 24).

El objeto principal de este folleto es exaltar a un general del siglo XIX Chalbaud Cardona y sus ideas liberales. Si bien es un folleto de los años setenta del siglo XX, Tejera ha tomado estos datos sobre Jacinto Plaza de la tradición oral de la ciudad e intenta relacionar a aquellos liberales con la figura de Jacinto Plaza -o viceversa-, "padre de los pobres", hombre justo que, a decir de Tejera, muy bien pudo haber sido liberal como Chalbaud. Aquí el muerto es recuperado para servir como modelo público para exaltar una ideología y uno de los hombres que la profesaba. Jacinto Plaza, en el imaginario de algunos escritores e intelectuales merideños se ha ido convirtiendo en una figura emblemática de la ciudad, que condensa el origen campesino e indígena, con una obra caritativa, un conflicto con la iglesia católica y los poderosos de la ciudad, una vida de comerciante, etc. La imagen de muerto milagroso, de "santo popular" se transforma en un héroe cívico, héroe de la ciudad, liberal e igualitario, hombre cuyas acciones "gloriosas" contra los poderosos de su época deben ser reconocidas y plasmadas en la "memoria colectiva"13. Este reconocimiento laico e intelectual, a pesar de su esfuerzo, en sentido contrario, tiene mucho de religioso y de alguna manera se vincula con el culto tradicional a los héroes de la patria. Como afirma Morin (1994, p. 46): ...en el interior de esta Patria, los muertos se hacen tan presentes como los vivos, más aún, los gobiernan. Son muertos consolidados, muertos que viven en el interior de los vivos, 'muertos que hablan'... No obstante, en la mayoría de los relatos este muerto se mantiene alejado de la 
política y se refiere más a su ayuda a los pobres y su conflicto con los curas, más que por problemas ideológicos porque un sacerdote le había quitado una mujer.

La historia de Alberto Carnevali no es tan conocida por sus devotos, no obstante por haber sido un dirigente político de $A D^{14}$ se hicieron varias biografías de él, pero no incluyen su figura como Muerto Milagroso (Rivas Aguilar, 1989). Carnevali nace en un pequeño caserío de Mérida, Mucurubá en 1914, de padre italiano y madre criolla. Estudió en la Universidad destacándose como periodista y político. Incursiona en este mundo desde muy joven, desarrollando una actividad gremial y participando en ella de manera protagónica; siempre fue un hombre público. Aunque se muda a Mérida en 1939, luego de la Revolución de Octubre (1945) será nombrado Gobernador de Mérida, a los treinta y un años de edad. Lo que destaca de su gestión es el viaje que hace a los Pueblos del Sur, en 1946. Con una comitiva regional gubernamental, visita durante quince días varios pueblos del sur del Estado Mérida (Mucutuy, Aricagua, Mucuchachí, Libertad y Guaraque) que por primera vez eran visitados por un gobernante moderno. Esto, probablemente, contribuyó a hacerlo conocido en una población que, años después, gran parte de ella emigraría a la ciudad de Mérida. Muchos informantes señalaban que era una persona muy querida, "muy dada", "era buena gente" y aunque era político "tenía mucho acercamiento con las comunidades". Se dedicará a la resistencia política contra Pérez Giménez, luego de la caída de Rómulo Gallegos. Varias veces es atrapado por el gobierno dictatorial. En 1949 es enviado al exilio, manteniéndose en la palestra política por medio de la prensa. Regresa a Mérida de manera clandestina y es apresado, aunque logra escapar de manera espectacular. En 1953 es capturado por última vez. Será confinado a la cárcel modelo de Caracas y luego a la de San Juan de los Morros, después de varios meses de prisión se le diagnostica cáncer en el estómago, muriendo poco después. Sus devotos, no obstante, afirman que fue asesinado en la cárcel. Su cadáver será enviado a Mérida para recibir sepultura. El gobierno intentó hacer el traslado de manera discreta pero sin lograrlo; de todos modos, la gente de los pueblos y de la ciudad de Mérida, "curiosa y rápidamente" se enteró del plan, reuniéndose por donde pasaba el cadáver de Carnevali. Su entierro se convirtió en un suceso público, según algunos incluso en un acto político contra el régimen. En los años ochenta del siglo pasado se abre el panteón donde estaba enterrado Carnevali para depositar el cadáver de un familiar, los testigos pudieron constatar que su cuerpo se mantenía conservado, al igual que los santos de la Edad Media. Es posible que su figura pública relevante y su muerte trágica lo convirtieran en un símbolo de resistencia y haya quedado prendado en la memoria colectiva, pero el hecho de que su cadáver se mantuviese conservado es una señal clara, en los relatos, de que no era un muerto cualquiera.

Machera, actualmente, es el muerto milagroso más importante de Mérida. Su tumba es seguramente la más visitada diariamente en el cementerio de El Espejo, superando el prestigio que gozaba en otra época Jacinto Plaza. Entre sus devotos los jóvenes menores de veinticinco años son numerosos; también se cuentan entre ellos los policías ("hombres de ley") y malandros que van a su tumba a solicitarle favores y protección. Machera era parte de una familia de origen cam-

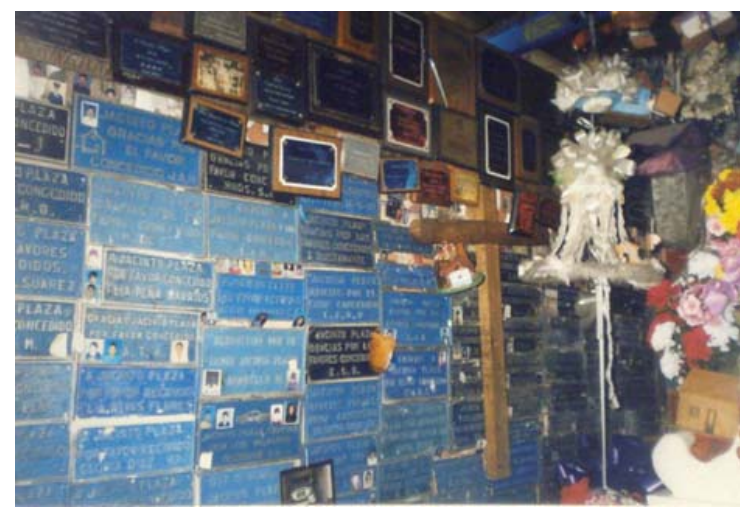

Figura 3 Pared del interior de la tumba de Jacinto Plaza, cubierta por completo por los exvotos dejados por los devotos a este muerto milagroso. Cementerio El Espejo. Ciudad de Mérida, Venezuela. Fotografía F. Franco

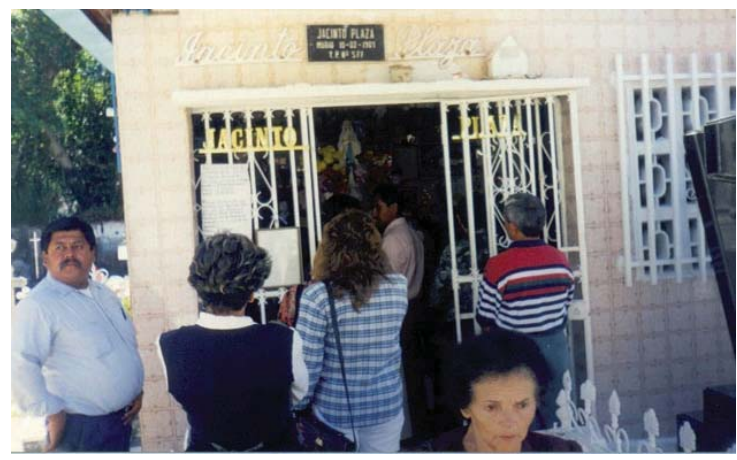

Figura 4 Entrada de la Tumba de Jacinto Plaza. Cementerio El Espejo. Ciudad de Mérida, Venezuela. Fotografía F. Franco

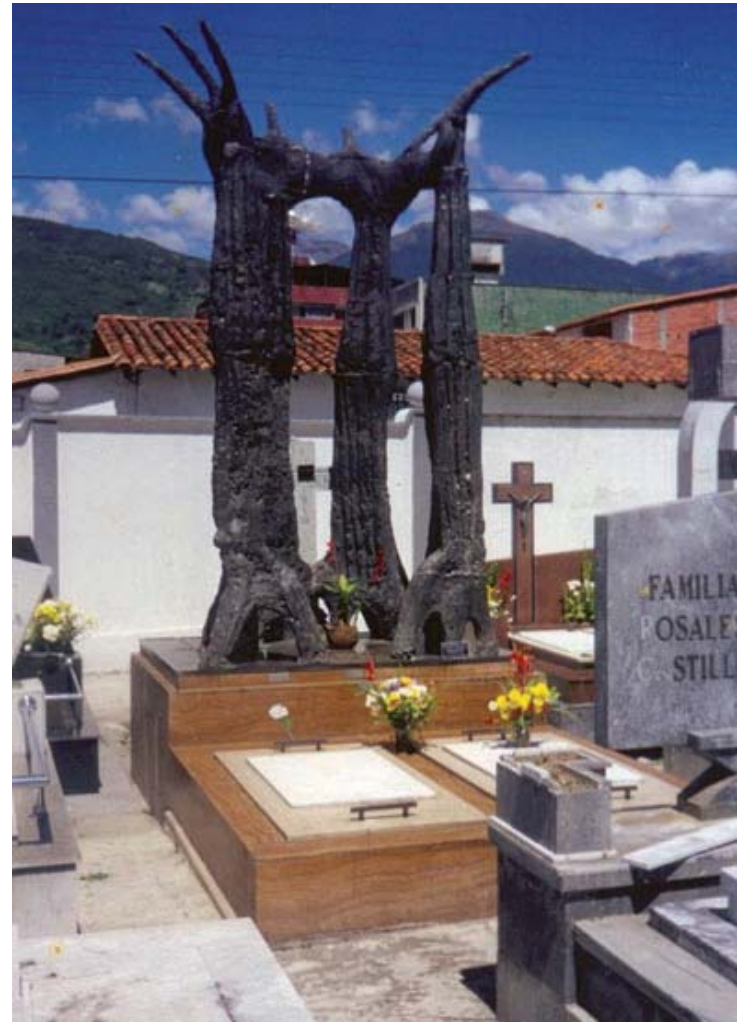

Figura 5 Tumba de Alberto Carnevali. Cementerio El Espejo. Ciudad de Mérida, Venezuela. Fotografía F. Franco 


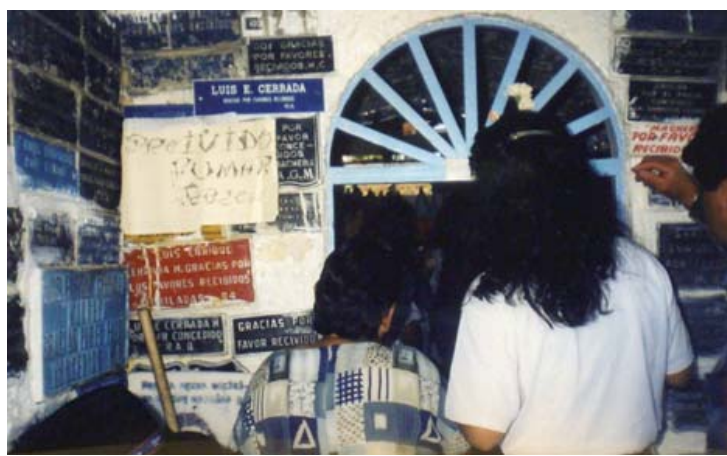

Figura 6 Entrada de la tumba de Machera. Cementerio El Espejo. Ciudad de Mérida, Venezuela. Fotografía F. Franco

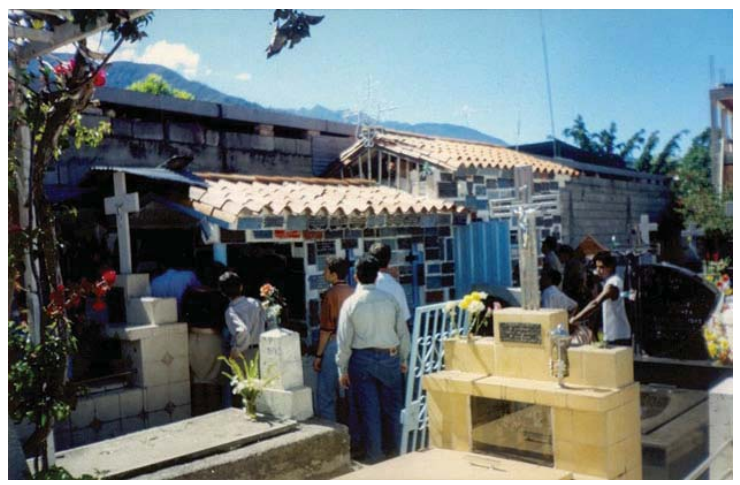

Figura 7 Tumba de Machera siendo visitadas por devotos. Cementerio El Espejo. Ciudad de Mérida, Venezuela. Fotografía F. Franco

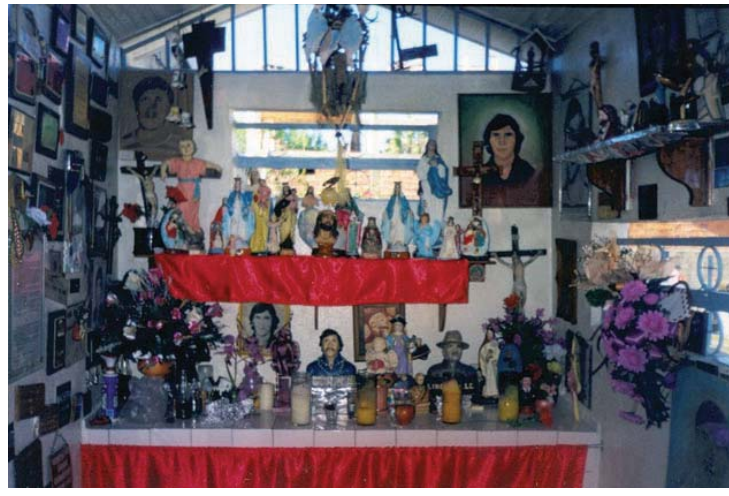

Figura $\mathbf{8}$ Interior de tumba de Machera, donde se observa el enorme altar con otros muertos milagrosos, espíritus de María Lionza y numerosos exvotos. Cementerio El Espejo. Ciudad de Mérida, Venezuela. Fotografía F. Franco pesino residenciada en el barrio de Santa Anita, al norte de la ciudad de Mérida. Nació el 28 de julio de 1956 y murió el 01 de octubre de 1977, de veintiún años. Cuando contaba con dieciocho o diecinueve años -tal vez más joven- viajó a Caracas y al centro del país, donde vivió por seis meses. Regresó de nuevo a Mérida a su barrio, allí se hizo conocido gracias a sus andanzas criminales, llegando a contar con su propia banda. También estaba vinculado con las drogas, era asesino y fue acusado de violación a mujeres. Era incluso temido por otros malandros. Se ganó su apodo (Machera) gracias que desde muy joven se arriesgaba constantemente y nunca mostraba miedo. Al momento de su muerte era uno de los malandros más buscados por la policía de la ciudad.

La muerte de Machera y la forma como murió causó gran revuelo en la ciudad. El suceso fue rápidamente difundido por la radio y por la prensa de la época, según cuentan los adeptos. Todo este evento en la memoria colectiva merideña quedó grabado como una huida heroica donde el motivo por el cual era perseguido pierde importancia, lo que interesa es la persecución misma como en las películas de acción, donde lo hiperbólico glorifica al personaje, así como el sufrimiento al cual es sometido al morir: Se montaba en los techos de las casas y brincaba huyendo de los policías; los policías le dispararon más de cien balas y todavía seguía huyendo; le metieron como cien balas y aún no moría. En la oración que todos los devotos le rezan es recordado "tristemente" y a pesar de ser un criminal, en la oración se reivindica su "destino glorioso", considerándose que está más cerca de dios que sus victimarios, gracias a la bondad que exhibió hacia los demás durante su vida. Su "solidaridad" se muestra en varias anécdotas, ya estereotipadas, que todo devoto cuenta: Una vez robó un camión de pollos y lo repartió entre su gente... la gente pobre, robaba farmacias para darle medicinas a quien necesitase, les daba potes de leche a madres solas y sin plata para sus hijos, robaba a los ricos para darle a los pobres. Se dice que fue muy querido en su comunidad y esto se refleja en el gran número de personas que lo acompañaron en su entierro.

Machera se distingue por una especie de rebeldía social o una lucha contra la desigualdad, así como otros muertos milagrosos guerrilleros y bandoleros de otras regiones de Venezuela ${ }^{15}$, no obstante, creemos que este rasgo apunta, más que a un imaginario sobre su liberación, hacia la acentuación de pertenencia a un grupo marginal, oprimido y cuya única salida hacia la superación social pareciera ser la violencia y la solidaridad entre el grupo. La bondad, el humanitarismo y la caridad de la que hablan los relatos de Machera ("no se metía con la gente de su comunidad", "robaba a los ricos para darle a los pobre") es "tribal" -si se nos permite el uso de este término, las otras comunidades no le preocupaban aunque fueran pobres; en el relato, el objeto de la bondad de Machera no es universal sino particular: su comunidad, su gente, su familia, su banda. La caridad es universal mientras que la solidaridad es particular: A diferencia de la solidaridad, la caridad se ejerce hacia todos (no excluye a nadie) y no se dirige más que a los seres que sufren o están amenazados; no hay peligro, aquí de contrariarla para asegurar mejores ventajas a un grupo... (Todorov, 1993: 91). Los relatos de Machera nos hablan de "solidaridad" y no de "caridad". Seguimos a Todorov (1993) en esta distinción: 
...La solidaridad en el interior de un grupo significa que ayudo automáticamente a todos sus miembros y que no me siento involucrado en las necesidades de quienes no pertenecen a él... La solidaridad hacia los míos implica la exclusión de los otros. Sus víctimas son pues los extraños, en todos los sentidos de la palabra... (p. 89).

El soldado Carlos Rojas es uno de los muertos milagrosos cuya historia es prácticamente desconocida. Los relatos sobre este muerto son más bien escasos y se puede afirmar que la mayoría no conoce su vida ni su muerte, solamente saben que fue un soldado, aunque existe gran cantidad de devotos que visitan su tumba, dejándole dinero y exvotos. Frecuentemente se refieren a él como "El Soldadito", lo que señala claramente la gran afectividad que los devotos sienten hacia este muerto; una constante en este culto. Un informante nos narró cómo murió El Soldado:

...antes cuando habian tomas de agua en Mérida, un soldado que estaba recibiendo órdenes, le fue encomendado abrir la toma de agua, pero sucedió que al abrir la toma de agua esta se lo llevó y murió. Parece que no tenía familia, igualmente lo trajeron al cementerio y lo enterraron. La tumba se la hicieron hace como quince años. [1983 ó 1984].

La particularidad de este muerto milagroso devela un rasgo que no es tan evidente en los relatos de otros muertos estudiados por nosotros: la servidumbre. El Soldado es el símbolo máximo de la obediencia, cuyo único objetivo es obedecer a sus superiores, incluso hasta la muerte, considerándose su muerte heroica, sin embargo estos dos soldados parecen haber muerto en la cotidianidad de su rutina, obedeciendo a sus superiores; la rebeldía, el carácter antisocial no aparece en los relatos de estos muertos, aunque sí una muerte violenta.

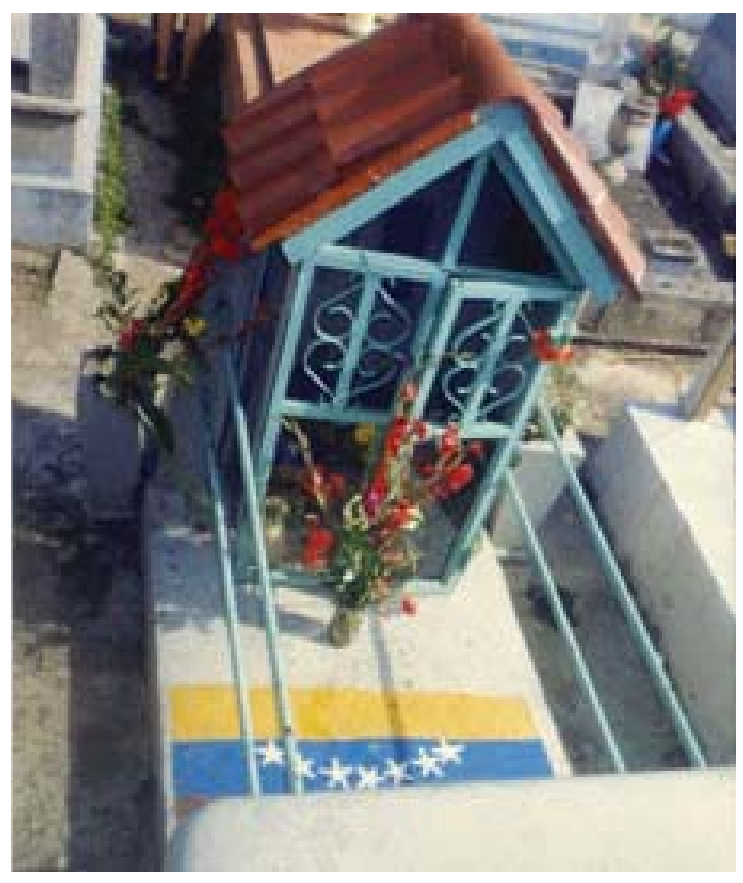

Figura 9 Tumba del Soldado Carlos Rojas. Cementerio El Espejo. Ciudad de Mérida, Venezuela. Fotografía de F. Franco
DE LOS RELATOS AL MITO: ¿SANTO POPULAR, HÉROE POPULAR O ESPÍRITU DE MUERTO?

Las breves "biografías míticas" que hemos resumido aquí, son los relatos acerca de personas que murieron y que luego de muertas son distinguidas por las personas que les rinden culto. Es la memoria colectiva de una comunidad acerca de la vida de estos personajes y de sus milagros y favores. La vida de estos personajes no corresponden con el modelo de los grandes héroes o de los grandes santos cristianos, ni gloriosos ni ascéticos. Los relatos acerca de sus vidas pendulan entre lo cotidiano, lo sencillo a lo violento, la desmesura o el sinsentido. Los relatos, que sobre los muertos milagrosos cuentan sus devotos y creyentes, son considerados por estos como "absolutamente verdaderos", sagrados y llenos de afectividad. Muchos de ellos tienen su hagiografía, escrita por devotos católicos que desean que la Iglesia católica los tome en cuenta para ser canonizados.

De estos relatos no nos interesa tanto la "verdad histórica", aunque es parte de ellos, si no los rasgos que conforman a estos personajes que se han convertido en verdaderos héroes en el sentido clásico del término: intermediarios, pero no ya entre los dioses y los hombres sino entre la muerte, las enfermedades, las vicisitudes, la mala suerte, los accidentes, los problemas, etc. y el hombre mismo. No van más allá de los límites de los hombres sino que han actuado en los límites de lo social y allí se han individualizados gracias a su muerte violenta, a la mala muerte, a la muerte que no ha seguido las vías o reglas sociales "normales".

Al igual que muchos mitos de otras culturas, las historias sobre estos muertos milagrosos a primera vista -así como el mismo culto- parecen o resultan escandalosas, inexplicables o absurdas. Lo que nos hace entender que tradicionalmente hayan sido tratadas por eclesiásticos, historiadores e incluso por los antropólogos como simple folclore, superstición o una especie de defecto del imaginario popular de Latinoamérica. Un malandro que es sacralizado luego de muerto (Machera); un ateo y anticlerical confeso en cuya lápida se escribe un pasaje de la Biblia (Jacinto Plaza); un político "santo" (Carnevali).

La elevación de estas figuras en muertos milagrosos implica la reunión de valores contradictorios. La individualidad del muerto milagroso es por un lado reivindicada y por el otro socializada. Estos personajes, según los relatos, tuvieron una vida singularizada, fueron de alguna manera distintos a todos los demás, pero, a la vez, como todos. La figura del oxímoron aquella en la que dos rasgos contrarios, que se excluyen mutuamente, se muestran en un mismo sujeto) expresa muy bien la paradoja que encierra la figura de los muertos milagrosos: son aceptados y rechazados socialmente, se les reconoce una vida única pero a la vez son recuperados por ser "muy queridos" por su comunidad, en algunos casos son temidos y odiados. Pero esa contradicción se concilia con la muerte, es cuando su individualidad recrece, aumenta, se prolonga, pervive en el relato de sus vidas y sus favores.

La muerte de estos personajes ha conmovido a sus comunidades hasta el punto de hacerlos sagrados, condensan las contradicciones más humanas que no pueden manifestarse en figuras tan abstractas como los dioses o en los modelos a seguir propuestos por el poder. Lo que expresan estas figuras 
es un cuestionamiento radical de lo que la sociedad formula como modelo positivo y, paralelamente, suavizan las perturbaciones que provoca el erigir la figura heroica como un antimodelo a seguir. Marc Augé (1993) precisa que el tema del héroe delimita la discusión, siempre paradójica y problemática acerca de la relación entre individuo y sociedad.

...lo imaginario específico de una sociedad, la existencia de héroes cosmogónicos y civilizados o símbolos de historia y de cultura (pero, más aún, de problemática humana) nos invita a interrogarnos acerca de los rasgos recurrentes de las configuraciones del poder y acerca de los límites intelectuales del pensamiento de lo social: si toda sociedad se define por un orden, la humanidad que lo constituye, sin embargo, sigue siendo un escándalo en relación con dicho orden; la oposición del individuo y la sociedad es una manera de expresar este escándalo, $y$, desde este punto de vista, las figuras heroicas (colmo y negación del individuo, colmo y negación de la sociedad) son ejemplares. (p. 181).

\section{NOTAS}

1. No es el tipo de presencia que tradicionalmente se ha atribuido de manera estereotipada a los mexicanos, una obsesión por la muerte, no temerle a la muerte, no hacer diferencia entre la vida y la muerte, etc. (Brandes, 2007, pp. 31-51). Donde el autor nos muestra que los estereotipos sobre la visión mexicana de la muerte constituyen, más que datos sobre la realidad, un imaginario que han construido escritores, investigadores, etc., mexicanos y extranjeros sobre la identidad del mexicano. Parece existir un estereotipo del latinoamericano, como el del latin lover o del gobernante corrupto y déspota, que lo distingue e identifica por una acentuada preocupación, o des-preocupación por la muerte. Se evidencia en las diversas y 'exóticas' creencias y rituales fúnebres latinoamericanos que ahora se publicitan en los famosos canales de cable de divulgación científica y en miles de páginas web en internet, sin embargo, todo estereotipo supone alguna 'verdad' acerca de la realidad que intenta simplificar... (Franco, 2009, p. 70).

2. Un ejemplo reciente es la exhumación del cadáver del Bolívar por parte del presidente Chávez para "verificar" si lo habían asesinado o no, lo cual creó todo un revuelo a favor y en contra. Unos veían en este acto un sacrilegio, otros la prueba de que el presidente era bolivariano y vinculado de manera especial a Bolívar. Ver http://www.elmundo.es/ america/2010/07/16/venezuela/1279300516.html; http:/ /cronicasmundosocultos.blogspot.com/2010/07/ exhumacion-de-los-restos-de-bolivar_17.html y revisar youtube. Sin embargo el uso político de la figura del Libertador no es nueva en Venezuela. Es además un muerto milagroso al que se le pide favores y es uno de los espíritus más importantes en María Lionza (Carrera Damas, 1973; Salas de Lecuna, 1987; Franco, 2009, pp. 1985-195).

3. El culto a María Lionza, como lo llaman los investigadores, o espiritismo, como lo llaman sus adeptos, es una religión que se desarrolló en Venezuela en los años cincuenta del siglo pasado en los barrios de Caracas y se difundió por toda Venezuela. Tiene como mito central la figura de una deidad femenina de origen indígena: María Lionza. Ha incorporado elementos católicos, indígenas y de origen africano, así como del espiritismo kardeciano, rasgos del curanderismo tradicional e incluso de la medicina occidental moderna. Es un culto de posesión, la "materia" (o médium) es la persona que "recibe" en su cuerpo a los distintos espíritus que son invocados en los rituales, cuando uno de estos "baja" toma posesión de la "materia". Estos espíritus son agrupados en cortes, noción que sirve para distinguir los distintos grupos de espíritus que existen en el culto (Corte Vikinga, Corte Africana, Corte India, Corte Médica, Corte Malandra, Corte de los Juanes, Corte Libertadora, etc.), a estas cortes están incorporados la mayoría de los muertos milagrosos. Hay una cantidad considerable de cortes que varían, desaparecen o aparecen de acuerdo con la formación, instrucción y personalidad de los oficiantes y creyentes. Los médiums a través de los espíritus ayudan a los creyentes a curarse física y "espiritualmente", luchan contra enfermedades y los daños mágicos que potencialmente otras personas pueden infligir, ayudan para la buena suerte, conseguir trabajo y para casi todos los aspectos de la vida (Clarac, 1992; García Gavidia 1987, 1996; Flores Díaz, 1990, 1996; Pollak-eltz, 1982; Franco, 2009, pp. 115-140).

4. En Venezuela es Ilamado también por algunos autores y por creyentes el Culto a las ánimas y Cultos a Santos Populares (Pollak-eltz, 1987). En Chile (Ojeda y Torres, 2011) curiosamente para nosotros se usa un término que abarca dos fenómenos, que aunque relacionados, se consideran aparte en Venezuela, los Muertos Milagrosos y Las Capillitas que se construyen a orillas de camino o en otros lugares por la muerte violenta o accidental que sufrió una persona en el lugar (Franco, 2009, pp. 90-96).

5. Esta es la capital del Estado Mérida, en el occidente de Venezuela. Es uno de los estados andinos de Venezuela, donde alcanzan las alturas más altas la cordillera andina. Es una ciudad que cuenta con una Universidad de alrededor de doscientos años de existencia. Es parte de una región tradicionalmente campesina, que ha sufrido un enorme crecimiento y cambio en las últimas décadas. Es también una zona turística. Es conocida en Venezuela como una ciudad "religiosa", lo cual se asocia a catolicismo. Sus habitantes como la mayoría de andinos venezolanos han emigrado muchísimo a todas partes de Venezuela.

6. En todas las regiones de Venezuela existen muertos milagrosos. Los más conocidos: José Gregorio Hernández, el Tigre de Guaitó, las Ánimas de Guasare, el Ánima de PicaPica, el Ánima de Taguapire, Lino Valles, María Francia, el Ánima de La Yaguara, Domingo Antonio Sánchez, el Ánima de Mata'e Silva, Guillermina Morales, Ismaelito, etc. Aunque hay una identificación regional con los muertos del lugar donde uno vive se pueden rendir culto y creer en muertos milagrosos de distintas regiones, todo depende de los relatos de los favores.

7. Uno de los casos más interesantes que pareciera cumplir con el modelo del santo católico es José Gregorio Hernández (Franco 2009:214-217; Suárez y Betancourt, 2000) científico de principios del siglo XX, nunca se dejó seducir por las filosofías modernas y se mantuvo como fiel creyente de 
Dios y la Iglesia católica, intentó ser sacerdote, e incluso monje de clausura, pero su débil salud no lo permitió, como médico se dedicó a los pobres, y murió atropellado por uno de los pocos vehículos que existían en 1919 en la ciudad de Caracas. Fue un médico dedicado a sus pacientes y ayudaba a los pobres en una época donde los médicos eran fundamentalmente para las personas pudientes. Su muerte violenta, espectacular, su "mala muerte" es uno de los elementos a tomar en cuenta para su transfiguración en muerto milagroso; en todo caso, los relatos de sus creyentes también lo reconocen como una persona "racista" porque no ayudó a un contemporáneo suyo, el también famoso científico Rafael Rangel, quien fue su discípulo y se suicidó. Cuentan los relatos que lo hizo porque no podía superarse debido a su "condición racial", era bastante moreno a pesar de las imágenes más contemporáneas que lo representan bastante más blanco. José Gregorio Hernández, sin embargo, es uno de los muertos milagrosos más populares en toda Venezuela y parte de Colombia. Por ello desde hace varias décadas ha sido postulado para ser canonizado por la Iglesia católica; no obstante, no ha pasado, a pesar de su popularidad y la adhesión de numerosos católicos fervorosos vinculados con la oficialidad eclesiástica, del primer eslabón en la cadena de canonización, el de venerable. La razón es que José Gregorio Hernández casi desde su muerte se le ha rendido culto como muerto milagroso, y además fue incorporado al espiritismo de María Lionza, siendo uno de sus espíritus más importantes y más solicitadas por los adeptos marialionceros. Es el jefe de la Corte de los médi$\cos$ (ver nota 4).

8. Establecimientos comerciales donde se puede conseguir materiales para rituales mágicos de todo tipo, desde hierbas hasta perfumes, libros, estampitas, imágenes, etc. Hasta hace poco eran conocidos como "perfumerías" de manera eufemística, en la actualidad han dejado de usarse esta identificación.

9. Existe una tradición antigua en Europa de exvotos similar a los milagritos en Venezuela: ...objeto reproducido y ofrecido a la divinidad en testimonio de gratitud: miembro curado (ojo, pierna, seno, vientre, etc.) navio en el que uno ha escapado de un naufragio, cadenas de un prisionero o de un condenado a galeras liberado... (Ariès, 1999, p. 238).

10. Uno de los textos es de Gabriel Picón Febres (1921), el otro de Tulio Febres Cordero (1923), devoto de este muerto, y publicado dos años después como respuesta al anterior. El primero es un texto con intenciones de hacer lo que se ha Ilamado "literatura oral" el segundo es hagiográfico (ver Franco, 2009, pp. 141-177).

11. Ver www.pereiraeduca.gov.co/instituciones/galeriadigital/ Espanol/Literatura/Doc_web/mitos\%20de\%20am\%E9rica/ rivera.htm. Consultado el 11/10/2005; Franco, 2009, pp. 141-177.

12. Oficio que durante la colonia y el siglo XIX, debido, en parte, a las dificultades para viajar en la época, gozó de gran prestigio.

13. Otro ejemplo: el uso de estos personajes durante los años de mandato del presidente Chávez. En este gobierno se ha promocionado de manera masiva el cine venezolano, por lo cual ha proliferado el número de documentales sobre ciertos muertos milagrosos como Machera (ver más adelante). Reivindicándolos en su condición de figuras populares que nacieron en Barrios, a pesar de haber sido malandros.

14. AD: Acción Democrática. Partido populista, llegó al poder en 1945 en un golpe cívico-militar. Luego es derrocado en 1948. Lideraron, junto con el partido Comunista, la resistencia a la dictadura de Pérez Giménez quien cae en 1958. Con la democracia en Venezuela $A D$ será el partido más importante con mayor apoyo popular hasta la llegada de Chávez al poder.

15. Montenegro, el Tigre de Guaitó, el Guerrillero de Santa Ana y otros son ejemplos de Muertos Milagrosos de Venezuela y de otras regiones de América Latina como el Gauchito Gil en Argentina y el Che Guevara en Bolivia, cuyas vidas estuvieron al margen de la ley. Son tan importantes que en el culto a María Lionza existe una "Corte malandra" a la cual pertenecería Machera, otros de la misma categoría son: Cesar Jesús Eloy González (Caracas), Antonio Rangel (Caracas) y el malandro Ismael o Ismaelito (Caracas). Acerca de estas ánimas o espíritus malandros dice Ferrándiz Martín (1995, p. 163): ... en su gran mayoría son delincuentes muertos en peleas callejeras, son uno de las últimos desarrollos en el seno del panteón del culto, y están vinculados a las nuevas configuraciones de violencia que están tomando forma en Venezuela en los últimos años...

\section{BIBLIOGRAFÍA}

Alberro, S. (2000). "Retablos y religiosidad en el México del siglo XIX". En Retablos y exvotos. (pp. 14-25). México: Museo Franz Mayer, Artes de México.

Ariès, P. (1999). El hombre ante la muerte. Madrid-España: Editorial Taurus.

Augé, M. (1993). El genio del paganismo. Madrid: Muchnik Editores.

Blanco, C. (1988). Manual Esotérico. Chacao-Miranda: Editorial Celia Blanco.

Brandes, S. (2007). "Visiones mexicanas de la muerte". En Flores Martos, J. A. y Abad González, L. (Coordinadores). Etnografías de la muerte y las culturas en América Latina (pp. 31-51). CuencaEspaña: Ediciones de la Universidad de Castilla-La Mancha.

Briceño Guerrero, J. M. (1994). El Laberinto de los tres minotauros. Caracas: Monte Ávila Editores.

Carrera Damas, G. (1973). El culto a Bolívar. Caracas: Ediciones de la Biblioteca de la Universidad Central de Venezuela.

Clarac de Briceño, J. (1992). La enfermedad como lenguaje en Venezuela. Mérida: Consejo de Publicaciones. Universidad de Los Andes.

Delgado, M. (1993). “La 'religiosidad popular'. En torno a un falso problema”. En Gazeta de Antropología. № 10. Granada-España. Recuperado de http://www.ugr.es/ pwlac/10_08Manuel_ Delgado.html. Consultado el 10/05/2009.

Febres Cordero, T. (1923). "El alma de Gregorio Rivera". En Archivo de Historia y Variedades. Tomo II (pp. 303-319). Caracas: Parra León Hermanos Editores. 
Ferrándiz Martín, F. (1995). “Itinerarios de un médium: espiritismo y vida cotidiana en la Venezuela contemporánea". En Antropología, № 10, octubre. Recuperado de http://europa.sim.ucm.es/compludoc/AA ? articulold=29100. Consultado el 20/10/2008.

Flores, D. (1996). La adivinación por el tabaco en el culto a María Lionza. Maracaibo: Vicerrectorado Académico, La Universidad del Zulia.

Franco, F. (2009). Muertos, fantasmas y héroes. El culto a los muertos milagrosos en Venezuela. Mérida: Consejo de Publicaciones, Consejo de Desarrollo Científico, Humanístico y Tecnológico. Universidad de Los Andes.

García Gavidia, N. (1987). Posesión y ambivalencia en el culto a María Lionza. Notas para una tipología de los cultos de posesión existentes en la América del Sur. Maracaibo: Universidad del Zulia, Facultad Experimental de Ciencias.

__ (1996). El arte de curar en el culto a María Lionza. Maracaibo: Vicerrectorado Académico, La Universidad del Zulia.

Ojeda L., L. y Torres B., M. (2011). Animitas. Deseos cristalizados de un duelo inacabado. Santiago de Chile: Consejo Nacional de la Cultura y las Artes.

Morin, E. (1994). El hombre y la muerte. Barcelona: Editorial Kairós.

Picón Febres, G. (1921): "El crimen de Gregorio Rivera". En Anécdotas y Apuntes (pp. 161-175). s/I.: Impreso por Primitivo Quero Méndez.

Pollak-eltz, A. (1982). Medicina popular en Venezuela. Caracas: Biblioteca de la Academia Nacional de la Historia.

_. (1987). Las ánimas milagrosas: Aspectos del catolicismo popular en Venezuela. Caracas: Universidad Católica Andrés Bello.

Rivas Aguilar, R. (1989). Alberto Carnevali: Pasión de Libertad (Escritos). Tomo I, Mérida: Universidad Popular Alberto Carnevali, Acción Democrática.

Salas de Lecuna, Y. (1987). Bolívar y la historia en la conciencia popular. Caracas: Universidad Simón Bolívar. Instituto de Altos Estudios de América Latina.

Suárez, M. M. y Betancourt, C., (2000). José Gregorio Hernández, del lado de la luz. Caracas: Fundación Bigott.

Tejera, H. (1974). “Carta a Mérida Andina. El General Esteban Chalbaud Cardona”. En Semblanza de dos ilustres merideños. Mérida: Editorial Venezolana.

Todorov, T. (1993). Frente al límite. México: Siglo Veintiuno editores.

// 